\title{
Editorial
}

\section{Educação na saúde - educação dos profissionais de saúde - um campo de saber e de práticas sociais em construção}

Laura C. M. Feuerwerker

As indefinições começam pelo nome. Educação em Saúde. Educação na Saúde. Como se chama o campo temático em que se inclui a educação dos profissionais de saúde? Educação dos profissionais de saúde é o mesmo que formação dos profissionais de saúde? Educação formal - na graduação e na pós-graduação - pode/deve ser tratada no mesmo campo em que a educação depois de formado, quando já trabalhando, campo da educação continuada e da educação permanente?

Educação dos profissionais de saúde tem uma importância grande na conformação de conceitos e de práticas na área da saúde. Movimentos de reestruturação na educação e nas práticas de saúde se entrecruzam, com atravessamentos e/ou transversalidades. O relatório Flexner e a iniciativa da Medicina Preventiva são exemplos significativos disso - um bem, e o outro mal-sucedido.

Reflexões críticas sobre a formação em saúde estão presentes na agenda de certos movimentos há praticamente 50 anos. Inicialmente, eram poucas as vozes; hoje, em função de uma série de elementos do contexto político e econômico -no âmbito tanto das políticas públicas como do setor privado -, há significativos contingentes de professores, estudantes e gestores da saúde envolvidos em iniciativas de mudança.

Ao longo dos últimos 15 anos de implementação do SUS, foram sendo acumuladas experiências e reflexões a respeito dos limites e possibilidades de diferentes iniciativas de mudança na formação dos profissionais de saúde.

Então, em comum com o movimento da reforma sanitária brasileira, o movimento de mudanças na formação tem o compromisso ético-político com a saúde da população brasileira e com os princípios do SUS.

Houve quem pensasse que esse compromisso ético-político genericamente traduzido num conceito ampliado de saúde e no compromisso com a construção do SUS fosse suficiente para orientar mudanças na formação. Houve quem pensasse que a questão central fosse a transformação das concepções pedagógicas, do papel e das relações entre docentes e estudantes no processo de produção do ensino-aprendizagem. Houve quem destacasse a complexidade da transformação institucional implicada em mudanças profundas na formação construídas no interior de instituições de ensino bastante tradicionais e conservadoras, atravessadas por compromissos e interesses corporativos e privatistas. Houve quem percebesse ser muito difícil mudar a formação sem, simultaneamente, transformar as práticas de saúde. É necessário, então, compreender a natureza do trabalho em saúde e suas especificidades, a conformação dos diferentes arranjos tecnológicos envolvidos em sua produção e os diferentes compromissos ético-políticos que eles implicam. Mas como produzir essas transformações trabalhando com mais indagações do que com respostas? 
Todas essas são questões pertinentes. A vivência de diferentes experiências tem, portanto, revelado a necessidade de um alargamento teórico-conceitual para pensar e construir as mudanças.

É preciso, então, reconhecer que educação na saúde é um campo de produção de conhecimento, necessariamente inter/transdisciplinar, em que os entrelaçamentos entre filosofia, ciência, técnicas, tecnologias e práticas sociais se apresentam de maneira específica.

Educação na saúde é um campo de saberes e de práticas sociais em pleno processo de constituição/construção. Há tensões e disputas na definição de suas temáticas centrais e na maneira de abordá-las. Há tensões e disputas nos movimentos "antropofágicos", de combinação de referências que muitas iniciativas de mudança operam na prática.

Há teses e dissertações, mas há poucos programas de pós-graduação especificamente nesse campo. Há núcleos e pesquisas, mas poucas linhas de financiamento específicas. Não há sequer como classificar a produção nesse campo, e há limitado espaço editorial para sua publicação.
Há pouca sistematização do conhecimento produzido nas iniciativas inovadoras. Parte significativa dessa produção limita-se a relatos de caso. Há poucas iniciativas de avaliação que dêem conta da complexidade dos processos. E as ferramentas/técnicas/referências tradicionais não se têm mostrado potentes para tanto. Nesse campo, da produção da mudança na formação, há que reconhecer a necessidade de novas "caixas de ferramentas" para a produção de conhecimento, levando em conta a implicação dos sujeitos - autores e atores dos processos em análise.

Educação na saúde, então, é um campo a ser trabalhado do ponto de vista da produção de conhecimento e das práticas sociais. Essa é uma tarefa para todas as profissões da saúde. Mais: é uma tarefa para todos os campos de saber entrecruzados com a saúde e com a educação na produção do compromisso ético-político que norteia o movimento da reforma sanitária brasileira. Precisamos produzir os espaços (inter)institucionais e as articulações técnico-políticas necessárias para dar conta desse desafio! 